\title{
Determinants of Recent Economic Growth in Ethiopia
}

\author{
Bulo Feyisa ${ }^{1}$, Tadele Feyera ${ }^{2}$ \\ ${ }^{1}$ Department of Economics, Jinka University, Jinka, Ethiopia \\ ${ }^{2}$ Department of Economics, Addis Ababa University, Addis Ababa, Ethiopia \\ Email address: \\ feyisabulo16@gmail.com (B. Feyisa), bulo.feyisa@jku.edu.et (B. Feyisa)
}

To cite this article:

Bulo Feyisa, Tadele Feyera. Determinants of Recent Economic Growth in Ethiopia. International Journal of Industrial and Manufacturing Systems Engineering. Vol. 5, No. 1, 2020, pp. 6-13. doi: 10.11648/j.ijimse.20200501.12

Received: January 31, 2020; Accepted: March 11, 2020; Published: April 28, 2020

\begin{abstract}
This study tried to identify the major sources of recent economic growth in Ethiopia for the last thirty three years starting from the year 1980 up to 2013. The study has been under taken with the use of both econometric and descriptive analysis techniques and various diagnostic tests like stationary test (by using augmented dicky-fuller test), multicollinearity test by using vif test), heteroscedasticity test (by using Breusch-pagan test), omitted variable (by using ov-test) both in the lung-run and short-run effect of independent variables on dependent variable. In addition, tables, figures and graphs were used. The study employed time series data for both the dependent (RGDP) and independent variables. The explanatory variables including domestic investment, labor force growth, real effective exchange rate, remittance and corruption were investigated. The analysis is carried out through an extensive review of relevant literature and macroeconomic model of economic growth. The findings show that growth in Ethiopia is positively affected by domestic investment, labor force growth, and remittance. Therefore, the study recommended that increasing domestic investment through promoting public and private sectors, effective use of the growing labor force and proper use of remittance for capital formation and distribution over all sectors as the directions to achieve rapid and sustainable economic growth in Ethiopia.
\end{abstract}

Keywords: Economic Growth, Real GDP, Real Effective Exchange Rate, Ethiopia

\section{Background}

Societies in general aspire for development [1]. Economic growth explains much of the development aspect; countries spend much their resource and time in an effort to ensure sustained economic growth. The source of economic growth is a question great concern for many economists who are interested to know and search for factors enabling some countries to grow and develop while others are suffering from poverty $[2,3]$.

Countries spend much of their resources and time in an effort to ensure sustained economic growth. However, it is only some nations that had achieved highest level of development, while others on the bottom level of development and vicious circle of poverty and some others on the track of fast and sustained economic growth. Thus the difference in the level of growth and development of nations can be explained both in comparison among themselves and in terms of the time difference in one nation [2, 4]. As witnessed by the recent experiences some East Asian countries have recorded astonishing economic performances while the sub-Saharan Africa (SSA) countries have not been able to obtain the kind of sustained growth which commonly regarded as premise of development. Ethiopia belongs to SSA countries where poverty is wide spread though the country recently experienced appealing economic growth. For instance, according to international monetary fund (IMF) world outlook 2010 report, Ethiopian economy gross domestic product grew annually by average $11 \%$ through the years 2004 to 2009 [3].

The basic questions that follow are that; what are the factors for the economic growth? That is, what the sources of economic growth are? What factors are more relevant for developing countries particularly to Ethiopia?

Populations, physical and human capital, level of technology saving internal trade, etc are considered source of economic growth in most countries. Such factors which can be determined by the competitive market economy may be relevant enough to explain the economic performance of the developed economy. But such conventional determinants cannot fully explain the growth process of developing economies. The growth function of developing countries 
differs from that of the developed countries [3].

Ethiopia, as one of the least developed country, shared this feature. Growth performance in Ethiopia is largely determined by political economy factors; vagaries of nature; strength and efficiency of institutions; efficiency of public policies and risk related to war and property ownership product and input market are found to be not only thin but also inflexible [5].

National economic policies, which are influenced by political factors and institutional settings, do also have strong correlation with economic growth. Macroeconomic policies and external factors do play significant role in determining short-run economic growth performance [3].

Ethiopia is a nation with long history of existence; history of independence and history of war. It is with a population of more than 80 million, plenty of resources, large arable land and etc. Though is with these and other potentials to grow, it is one of the poorest countries in the world with $29.2 \%$ of its population living below the poverty line and a per capital income of below $\$ 1500$ a year [6]. But assessment of the Ethiopian economy still indicates low level of living standard, low level of domestic saving, weak private investment, extremely low foreign investment inflow, unemployment and poor social and physical infrastructures [2]. The study will try to examine both economic and non-economic determinants, which are believed to be very much relevant in explaining the growth performance in Ethiopia.

\section{Objectives of the Study}

\subsection{General Objective}

The main objective of the study is to examine the major determinants of growth in Ethiopia.

\subsection{Specific Objectives}

Specifically the studies try:

1. To analyze the major determinants of economic growth in the country.

2. To overview the economy in the study period

\section{Model Specifications and Methodology}

\subsection{Model Specification}

Economic theory is mainly concerned with relations among economic variables. This relation is presented in terms of smooth curves or precise equations or statements /hypothesis that are mostly of qualitative nature.

Economic statistics is concerned with descriptive statistics (collecting, processing and presenting economic data) while econometrics utilizes this data to estimate the quantitative economic relations ships and test hypothesis about them.

Mathematical statistics deals with statistics from mathematical point of view using probability theory and branch of mathematics. Mathematical economics is concerned with application of mathematical method to represent economic theory. Both mathematical statistics and mathematical economics provide tools/ models used in econometrics.

Model specification refers to mathematical demonstration of the relationship between variables that is dependent variable and independent variable. Real gross domestic product (RGDP) is specified as a function of real effective exchange rate (REER), labor force (LF), domestic investment (DI), remittance (RIM) and corruption (CORR). So the model for this study is specified as follows.

RGDP $=\mathrm{f}($ CORR, DI, REER, LF, RIM $)$

By introducing the intercept term and the error term in to the above equation we can have the following equation.

$$
\mathrm{RGDP}=\beta 0+\beta_{1} \mathrm{CORR}+\beta_{2} \mathrm{DI}+\beta_{3} \mathrm{REER}+\beta_{4} \mathrm{LF}+\beta_{5} \mathrm{RIM}+\varepsilon \mathrm{i}
$$

Where;

RGDP=real gross domestic product (real output)

$R E E R=$ real effective exchange rate

$\mathrm{LF}=$ labor force

$\mathrm{DI}=$ Domestic investment

RIM=remittance

$\mathrm{CORR}=$ corruption

$\varepsilon \mathrm{i}=$ error term (stochastic disturbance)

\subsection{Descriptions of the Variables and Expected Sign}

Real gross domestic product: the total value of goods and services in the economy over one year period. it has implications of factor supplies, infrastructure and total factor productivity thus being affected by the above determining factors.

Real effective exchange rate: exchange rate adjustments are also a potential source of growth. it is used to determine an individual country currency value relative to other major currency in the index, as adjust to the effect of inflation. The adjustment in the relative price of tradable and non-tradable implied by devaluation to increase the overall price level. It has direct impact on growth by increasing volume of export and foreign direct investment (FDI), that is devaluation affects the terms of trade and balance of payment of the country positively; $\beta_{3}>0$

Labor force (LF): theoretically labor force is the engine of growth. But it seems opposite for many African countries even becoming a burden for the economy because of high rate of unemployment. From time to time unemployment rate is increasing still those who are formally and informally are playing crucial role in economic growth of the country [7]. The expected sign of the coefficient of actual labor force is positive; $\beta_{4}>0$ the Domestic Investment (DI): investment is part of national income of expenditure devoted to the product of capital goods over period of time [8]. Investment is a flow of funds towards spending that adds to physical stock of CapitaLand determines the rate at which the economy adds to its stock of physical capital and thus, it helps the economy's long run growth and productivity performance [9]. Domestic investment is positively related to GDP, i.e. as GDP increases income also increases and this intern increases market demand and this makes investors to Invest more. The expected sign of the coefficient of investment is positive; $\beta_{2}>0$ 
Remittance (RIM): Are the financial flows associated with migration in other words personal cash transfers from a migrant worker or immigrant to relatives in the country of origin [3]. Studies show that remittance contributes to economic growth through their positive impact on consumption, saving and investment. The expected sign of the coefficient of Remittance is positive; $\beta_{5}>0$.

Corruption (CORR): is an effort to secure wealth or power through illegal means for private gain at public expense; or a misuse of public power for private benefit (Transparency International). Corruption adversely affects economic growth hence development largely by reducing private investment and possibly by altering the composition of government expenditure, specifically by lowering the share of spending on education. The expected sign of the coefficient of Corruption is negative; $\beta 1<0$.

\subsection{Methodology}

Econometrics is the application mathematical methods to the analysis of data, with a purpose of giving empirical content to economic theories and varying or refuting them [8].

Since this study employs a time series data, it is mandatory a stationary of the data to be tested. A stochastic process is said to be stationary if the mean and the variance are constant regardless of the time taken. Stationary test make sure that there will not exist a spurious which is often found in nonstationary time series. If the data is non-stationary, forecasting the result to the other time period may not have practical significance [8].

Treating non-stationary time series as if they were stationary will bias the ordinary least square (OLS) and the result in misleading economic analysis. For example, the model systematically will fail to predict outcomes and can also lead to the problem of spurious (misleading) regression where R-squared is approximating unit's' and ' $\mathrm{f}$ ' statistic look significant and valid.

Before any time-series econometric model is estimated, appropriate tests of the variables must be taken place to observe their time series properties.

Unit root test

In economics a time series that has a unit root test is known as a random walk which is an example of unit root in macroeconomics data is at least profound of a structural variable, such a real output is truly I (1), then shock to it will have permanent effect.

Method of testing for unit-root test;

Dickey-Fuller (DF) test

$\mathrm{y}_{\mathrm{t}}=\mathrm{y}_{\mathrm{t}-1}+\epsilon_{\mathrm{t}}$ when the coefficient of $\mathrm{y}_{\mathrm{t}-1}$ is one, we face the problem of unit-root or non-stationary. That is, the solution set of the characteristic equation is unity and hence, $y_{t}$ is nonstationary. Using lag operator $\mathrm{yt}=\alpha \mathrm{Ly}_{\mathrm{t}}+\epsilon_{\mathrm{t}} \rightarrow \mathrm{yt}-\alpha \mathrm{Ly}_{\mathrm{t}}=\epsilon_{\mathrm{t}} \rightarrow$ $(1-\alpha \mathrm{L}) \mathrm{y}_{\mathrm{t}}=\epsilon_{\mathrm{t}}$ equation is: $1-\alpha \mathrm{L}=0 \rightarrow \mathrm{L}=1 / \alpha \rightarrow(\alpha=1)$ Thus, when the solution set of characteristic equation is unit root, our time series data are non-stationary.

Co-integration Test

The concept of co-integration is used to take care of the non-stationary of variable and to examine whether there is the long run relationship among the variables under consideration. It is also shown that even though the variables taken separately are not stationary; their linear combination (taking together) may be stationary. In such a case the variables are said to be co-integrated series, is spurious and hence, it enable establish long run relationship between dependent and independent variables (Gujarati, 2004).

Multicollinearity

It is a situation where the explanatory variables are highly inter-correlated is referred to as Multicollinearity. This makes difficult to disentangle the separate effects, of each of the explanatory variables on the explained variable (Madalla, 1984). Multicollinearity is not necessarily a problem unless it is highly relative parameter estimates would be very sensitive to the addition or deletion of the observations.

We can detect the problem of Multicollinearity through:

Smaller t-ratios but higher $\mathrm{R}^{2}$

Variance inflation factor (VIF) If $\mathrm{VIF}>=10$, Multicollinearity problem exists.

Deletion or addition of explanatory variable causes a large change in the estimates of the remaining coefficients.

If there is no Multicollinearity problem, the estimated coefficients are stable, even when some observations are deleted.

Alternative measures

1. Decrease correlation among the explanatory variables.

2. Combine variables which are conceptually related.

3. Drop some of the explanatory variables if they have significant coefficients.

4. Increase the variance of then explanatory variables.

5. Getting more data etc.

Heteroscadesticity

Heteroscadesticity refers to the distribution of the disturbance term when the distribution of the error term is not the same for various observations (i.e. if the error terms do not have a constant variance $\operatorname{Var}(\varepsilon i) \neq N(0, \sigma)$, then the disturbance term is said to be subjected to heteroscadesticity [6].

It can be caused due to:

1. Large variations in the size of entities for which the data are collected.

2. Outliers (exceptionally high or low values) which can increase or decrease variance.

Although the ordinary least squares (OLS) estimators are still linear and unbiased, they are inefficient.

Variance of the estimators are biased, thus, the test tests of significance based on them are invalid.

T-tests and F-tests are invalid in the presence of heteroscadesticity and hence generally, it leads to wrong statistical inference and the OLS estimation technique becomes in appropriate (Madalla, 2008).

Thus, we need alternative estimation techniques known as "Generalized list square (GLS)". This method transform the original variables in such a way that the transformed variables satisfy the assumptions of classical model and then apply the OLS estimation method and therefore capable of producing estimators that are BLUE. In short, GLS is OLS on the transformed variables that satisfy the assumption of 
classical linear regression model [8].

Auto correlation

The term auto correlation may define as correlation between members of series of observations ordered in time (as in time series data) or space (as in cross-sectional data. The classical linear regression assumes that such auto correlation does not exist in the distributions $u_{i}$, i.e., $E\left(u_{i}, u_{j}\right)$ $=0$, for all $\mathrm{i} \neq \mathrm{j}$. however, if there is such dependence we have auto correlation. Symbolically, E (ui,uj) $\neq 0$, for $i \neq j$. there are (n-1) auto correlation if we have $n$ observations. However, we cannot hope to estimate of all these from our data. Hence, we often assume that this (n-1) auto correlation can be represented in terms of one or two parameters [7].

Error correction model (ECM)

This step is taken if the variables are co-integrated. This mechanism of Engle and Granger correct of disequilibrium. If the error correction mechanism, the first difference of the dependent variables is regressed on the first differences of the explanatory variables and the first logarithm of the residual obtained from the long run model. If the equilibrium error term is statistically zero, the dependent variable adjusted to change in the equilibrium in the same period. However, if it is non- zero, then the model is out of equilibrium [8].

\section{Descriptive Analysis}

In this section the trend of the variables was revealed. The trend followed by various variables incorporated in the model with that of the trend of real growth domestic product. The aim of the trend is to serve as a base for the basic analysis which will be done based on the econometric results.

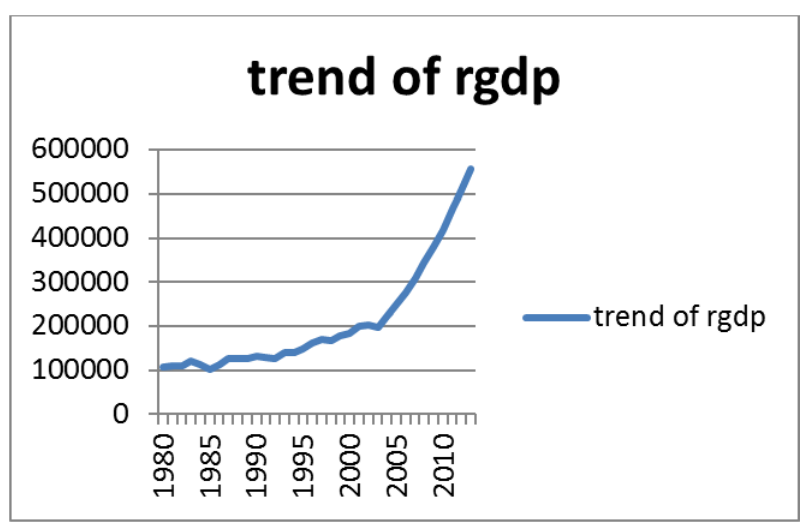

Figures 1. Growth of the economy in terms of RGDP.

Ethiopia has experienced strong economic growth in the recent years with real GDP growth faster that or near doubledigit level since 2003/2004. Ethiopia has consistently outperformed most in Africa and other countries and expanded much faster than the continent. At the same time, the country still faces some structural weakness that present significant challenge in the medium term. Rea GDP growth average $11.2 \%$ per annum during the $2003 / 2004$ up to $2008 / 2009$ period, placing Ethiopia among the top performing in Sub-Saharan Africa.

Trends of the major explanatory variable

\subsection{Domestic Investment}

Due to the higher state intervention in the economy over the last three decades the public sector investment is the major explanatory variables of the Ethiopian economy.

Particularly, due to the command economic orientation of the government and sever war and uncertainty in the country, in the first decade (1980-1994), the highest level of domestic investment spent on war. Since war is a negative sum game the economy deteriorated and went to recession and depression.

The next ten years (1994-2004) the economy was in rehabilitation and reconstruction. But year 1999/2000 was an exception. The country's attention and its investment diverted to war front once again. Thus there was breakdown the domestic investment. The last decade (2004-2013) was a decade of fast and sustained growth in the economy. The public investment on the basic sectors of the economy as roads, health, education, energy, etc was immense and productive. Government is the sole actor in the above mentioned and other sectors of the economy which built the basic necessity to growth and development and creates an enabling environment to the private sector.

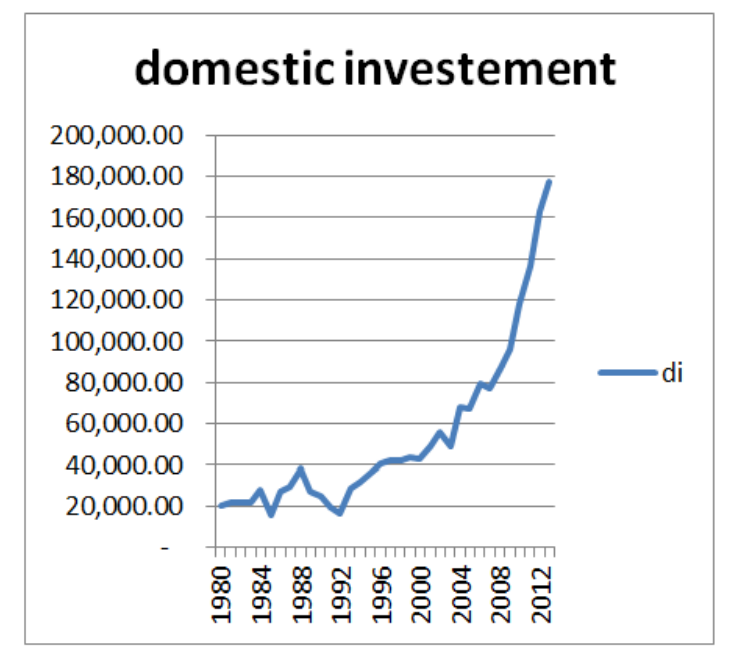

\section{domestic investement}

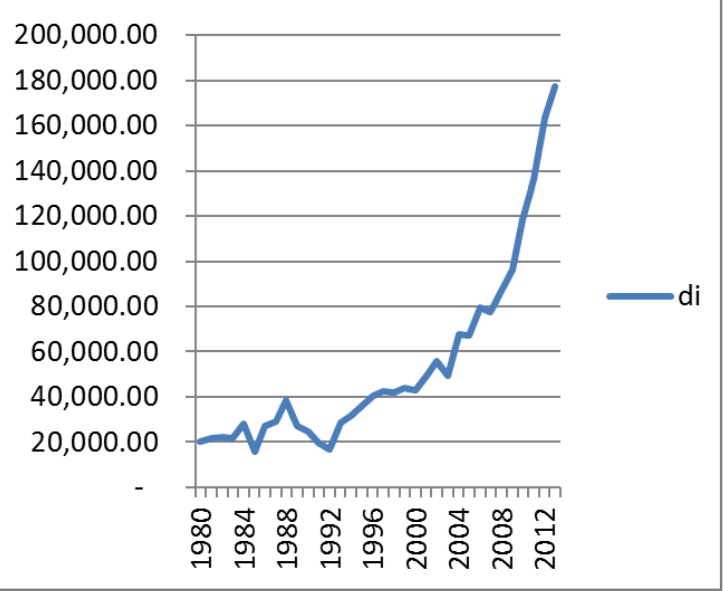

Figure 2. Trend of domestic investment. 


\subsection{Real Effective Exchange Rate}

Exchange rate defined as the number of units of foreign currency that can be purchased with one unit of domestic currency. Meaning, an exchange rate is the price of one nation's currency in terms of another nation's currency [5]. This study is concerned with the effect that movements in the exchange rate could have impacts on the economic growth of the country. In this analysis, exchange rate is defined as the unit of the home currency per unit of the foreign currency (for instance Birr $/ \$$ ). According to economic theories, depreciation could have negative or positive effect on the economy. The negative side, a depreciating currency results in high import prices which leads to increase in domestic prices and eventually inflation. The positive side also, a depreciating makes domestically produced goods more competitive on the export market and could increase the demand for those goods.

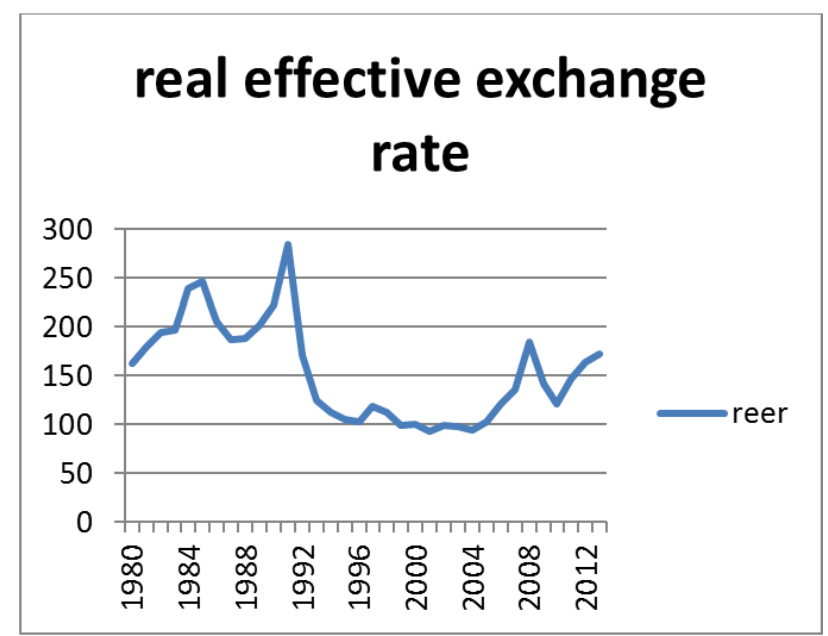

Figure 3. Trend of real effective exchange rate.

As observed from the above figure the real effective exchange rate of Ethiopia was fluctuating over time and it reach its maximum level in the between (1990-2012) or in the time of transition period then it reduce with high speed and again stared to rise in the 2006 .

\subsection{Labor Force}

Theoretically, labor force is the engine of development. But it seems opposite for many African countries even becoming a burden for the economy because of high rate of unemployment. From time to time unemployment rate is increasing. Still those who are employed formally and informally are playing crucial role in economic growth of the country (ILO, 2010).

Due to the fast increase in the population, over the last three decades the labor force of the economy growth considerably. It increases from 26.104 million in 1984 to 63.578 in 2013. But due to higher unemployment and underemployment the labor force is seen as a liability than an asset to the economy. However, evidence from the figure above shows that the labor force growth affects the economic growth of the country positively with less fluctuation and sustainable way.

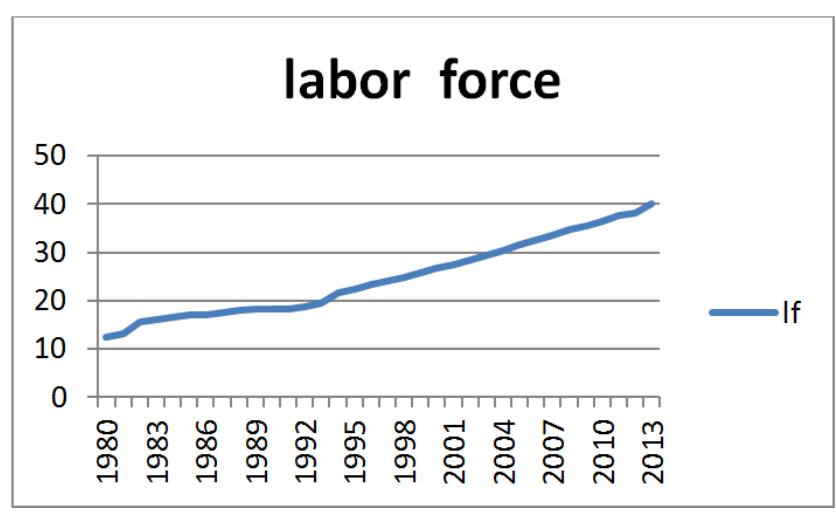

Figure 4. Trend of labour force.

\subsection{Remittance}

The financial flows associated with migration in other words personal cash transfer from a migrant worker or immigrant to relatives in the country of origin (International organization for migration, 2006). Studies show that remittance contributes to economic growth through their positive impact on consumption, saving and investment.

As observed from the above figure the contribution of remittance to the economic growth of the country was stagnant from the period 1980-1987 and started to rise in the year from 1988-2000 with less fluctuation. And it started to rise increasingly from the 2001 on wards, which shows that it affects the growth of the country significantly in the recent years.

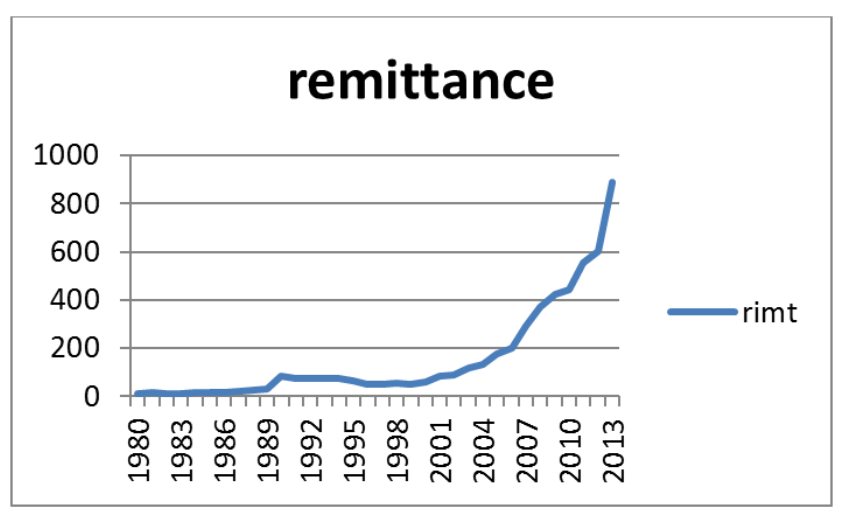

Figure 5. Trend of remittance.

\section{Econometric Analysis}

\subsection{Test for Stationary}

In the classical regression technique of ordinary list square (OLS), the variables are assumed to be non-stationary. But such non-stationary variables give spurious or non-sense regression, but to obtain non-spurious results variables have to be stationary. According to Gujarati (2004), a variable is said to be stationary if its mean, variance and covariance are time invariant or time inconsistent, it depends on lag length. 
If a given series contains unit root, then the series is said to be non-stationary otherwise, it is called stationary. Among the different methods of testing stationary of time series, the unit root test, it's recently developed and widely used test of stationary. The Dickey Fuller (DF) test and Augmented Dickey Fuller (ADF) test are the two among others and that are used to test for the existence of unit roots. In this study therefore, the variables are tested for unit root using Augmented Dickey Fuller (ADF) test is used. According to the test result all variables are stationary at first difference.

The long -run analysis

The long run model used to estimate the long run determinants of economic growth is

\section{$\mathrm{RGDP}_{\mathrm{t}}=\beta_{\mathrm{o}}+\beta_{1} \mathrm{DAACC}+\beta_{2} \mathrm{DI}+\beta_{3} \mathrm{REER}+\beta_{4} \mathrm{LF}+\beta_{5} \mathrm{RIMT}+\varepsilon_{\mathrm{t}}$}

The model with estimates of the long run coefficients is specified as follows

$\mathrm{RGDP}_{\mathrm{t}}=6.39699-$

$0.028695 \mathrm{DAACC}+0.196303 \mathrm{DI}+0.056108 \mathrm{REER}+0.880684 \mathrm{~L}$ $\mathrm{F}+0.125491 \mathrm{RIMT}$

\subsection{Test for Auto-correlation}

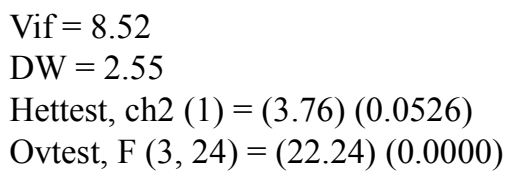

As can be seen from the regression, $\mathrm{R}^{2}$ and adjusted $\mathrm{R}^{2}$ of the long run model are high with value of $89.43 \%$ and $87.47 \%$ respectively this means $89.43 \%$ of the variation in the long run economic growth is explained by the variation in all explanatory variables included within the model. The overall significance of the model is tested using F-statistic as follows.
Ho: $\beta_{1}=\beta_{2}=\beta_{3}=\beta_{4}=\beta_{5}=0, \mathrm{H}_{1}: \neq$ Ho

The F-test which is against the null hypothesis (Ho) that all explanatory variables of the long run model taken together do not explain the dependent variable is rejected, implying that the independent variables jointly explain the dependent variable at $5 \%$ level of significance.

The individual significance of the coefficients is tested based on the following hypothesis.

Ho: $\beta \mathrm{i}=0 \mathrm{Hi} \neq \mathrm{Ho}$; the t-test for the individual significance of the coefficients show that Ho is not accepted for $\beta_{2}, \beta_{4}$ and $\beta_{5}$ where Ho is accepted for the remaining coefficients in the long run model at 5\% level of significance. Therefore only domestic investment, labor force and remittance are found to be the major explanatory variables of the long run economic growth and it proceed to interpretation, so they are both statistically and theoretically significant the sign of domestic investment, labor force and remittance are consistent with prior expectation. As can be observed from the result at $1 \%$ rise in domestic investment, will increase the economic growth of Ethiopia by $0.19 \%$, citrus paribus, similarly according to the long run result, a $1 \%$ rise in labor force, will increase the mean value of economic growth of Ethiopia by $0.88 \%$, with citrus paribus and a $1 \%$ rise in remittance, will increase the economic growth of Ethiopia by $0.12 \%$, citrus paribus. However, the coefficients for the variables corruption and real effective exchange rate are not statistically significant, even if the sign of corruption is consistent with prior expectation, but the sign of real effective exchange rate is inconsistent with prior expectation. The Durbin-Watson (DW) d-statistic test also reveals the absence serial correlation problem in the short run since its value around (near two) that is 2.5 .

Table 1. Test for Co-integration.

\begin{tabular}{|c|c|c|c|c|c|}
\hline Variable & Test statistics at level & Critical value (1\%) & Critical value (5\%) & Critical value (10\%) & Stationarity \\
\hline Residual(e) & -4.763 & -3.696 & -2.978 & -2.620 & At level \\
\hline
\end{tabular}

The concept of co-integration used to take care of the nonstationary of the variables and to examine whether there exist a long run equilibrium relationship among the variables under consideration (Gujarati 2004). The co-integration test shows that even though the variables taken separately may not be stationary at all level but are stationary of order one I (1), their linear combination must be stationary. In such case, the variables are said to be co-integrated, a co-integrated series is non-spurious and hence, it enable to established long run relation relationship between variables. Engle Granger (EG) two stage procedure and Johansson maximum likely hood approaches are among the method of testing cointegration. As Gujarati (2004), noted while using Engle Granger (EG) approach in the first step the long run model in level from which is integrated of order one, I (1) is estimated. Then we estimate the long run model and obtain the residual. Then after, we test the stationary of the residual which is the linear combination of variables. If the residual is stationary, the variables are said to be co-integrated, which means that they have long run relationship or exist a long run equilibrium relationship among the variables included in the model. From the estimated result the residual is stationary at all level of significance.

Table 2. Normality test.

\begin{tabular}{llllll}
\hline Variable & Obs & W & V & Z & Prob $>\mathbf{z}$ \\
\hline Residual (e) & 34 & 0.98198 & 0.629 & -0.966 & 0.83295 \\
\hline
\end{tabular}

In this study Shapiro-wilk W test for normality is used. As the test from the table indicates probability is greater than 0.05 i.e. it is normally distributed.

The short run analysis

The model generated is the following

$$
\mathrm{RGDPt}=\beta_{\mathrm{o}}+\beta_{1} \mathrm{DAACC}+\beta_{2} \mathrm{DI}+\beta_{3} \mathrm{REER}+\beta_{4} \mathrm{LF}+\beta_{5} \mathrm{RIMT}+\varepsilon_{\mathrm{t}-1}
$$

Where; ct-1 is the lagged residual is generated by taking one period lag of the variables

In the short run, the error correction model is estimated to determine the coefficient of the short run dynamics and to grasp how fast the disturbance in the short run coefficients 
adjusted to their long run value. The R-squared value for the short run dynamics is about 0.4053 . Meaning of R-squared $40.53 \%$ of the variation in the economic growth is due to explanatory variables involved in the model. The F-statistic witness shows that the explanatory variables of the short run model are jointly significant at 5\%level of significance.

The Durbin-Watson (DW) d-statistic test also reveals the absence serial correlation problem in the short run since its value around (near two) that is 1.75 . Regarding the individual significance and sign of variables the coefficient of domestic investment real is significant at $5 \%$ critical value and its sign was consistent with prior expectation. As the estimated result show with citrus paribus in the short run a $1 \%$ rise in domestic investment, will increase economic growth of Ethiopia by $0.21 \%$.

Although the sign for the coefficient of remittance, labor force and corruption are consistent with their prior expectation, they are not significant, therefore as the result reveals only domestic investment affects the economic growth in the short run, among the variables included in the model. The short run model also shows the lagged error term is negative with the magnitude of nearly 0.31 , the interpretation for this term is that, any previous shock in the short run will be adjusted by $31 \%$ each year to wards the long run equilibrium. In other words $31 \%$ the short run disturbance will be adjusted to the long run equilibrium per year.

\section{Conclusion and Policy Recommendation}

\subsection{Conclusion}

Economic development can be described as the transformation of societies. Economic growth which can be defined as sustainable growth in the real GDP or per capita GDP, explains much of economic development. This is because economic growth directly or indirectly encompasses other issues which explain development. For this reason, countries spend much of their resources and time in an effort to ensure sustainable growth.

Different factors are considered as factors for the growth process in different countries. This study tries to see the determinants growth in Ethiopia. As mentioned in the literature review and analysis part of this paper, the institutional political economy factors and natural factors are taken as given. Accordingly, the study used domestic investment, labor force growth, remittance, real effective exchange rate and corruption as major explanatory variables and real growth domestic product (RGDP) as the dependent variable in determining economic growth in Ethiopia.

As presented in the descriptive chapter the Ethiopian economy pass through various growth rates over the decades reaching the highest in the last decade of the study period. Accordingly economic performance in Ethiopia during 1980-2013, has been unsatisfactory. The study investigates the macroeconomic and other determinants of growth in Ethiopia during 1980-2013. The main finding can be summarized as follows:

Domestic investment (DI), labor forces (LF) and remittance (RIM) is significant and positively affect the GDP in long run, whereas, real effective exchange rate (REER) insignificant but positively affects the real GDP or growth in the long run.

In the short run only domestic investment (DI) has positive and significant effect on economic growth. Where remittance (RIM) and real effective exchange rate (REER) have positive but insignificant contribution to real GDP. On the other hand both labor force growth (LF) negatively but insignificantly affect economic growth.

In general, all explanatory factors are relevant in explaining growth process in Ethiopia in the long run. This shows the need to give due attention to all the variables under considerations, especially to the domestic investment which positively and significantly affects growth both in the long run and short run.

\subsection{Policy Recommendation}

Over the last one decade, though the Ethiopian economy is achieving relatively good performance as compared to the country's history and other African countries, the major macroeconomic and other indicators show that the country is still at bottom level of economic development and part of its population is living under poverty and backwardness.

Some works to be done include:

1. Government must invest in the physical and social infrastructure and other crucial sector which improves the economic performance of the country directly and indirectly through promoting domestic private and public investment in the economy,

2. In order to avoid the adverse effects of large work force, it demands creating job opportunities to the working population through; increasing public investment on the sectors with high potential of job creation, creating enabling environment for domestic investors and attracting foreign direct investment, increasing the growth process of the country etc.

3. Although remittance is both significant and positively affects the economic growth in long run, care should be taken how to manage it so as to use it in capital formation and distribute all over the sectors.

4. The government should increase domestic investment by promoting both public and private sectors through encouraging entrepreneurship and job creation so as to absorb the growing labor force in the long run in order to bring sustainable economic growth and the societal welfare

\section{References}

[1] Abelti Moti, (2010) "Determinant of Economic Growth"

[2] Alemeyew Geda, (2005): "Explaining African Growth Performance": The case study of Ethiopia, Addis Ababa University. 
[3] Barro Robert, (1996): "Determinants of Economic Growth": A cross country empirical study, MIT presses.

[4] Seid Nuru (2000), "Determinants of Economic Growth in Ethiopia" Addis Ababa University. Mankiw G. (2007): Macroeconomics, New York worth publisher, six editions

[5] Petrakos G. et al (2007): Determinants of Economic Growth: the expertise view, Working paper

[6] Maddala G. (1982): Introduction to Econometrics, second edition, University of Florida and Ohioh state University, MacMillan, Canada
[7] Jhingan L. (1989): The Economics of Development and Planning, New York.

[8] Gujarati D. (2004): Basic Econometrics MC Grew-Hill/Irwin, New York.

[9] Romer, Paul M. (1996): Why Indeed America? Theory, History and Modern Economic Growth; NBER working paper series, No. 5443, National Bureau of Economic Research.

[10] Seyoum, (1997): Economic performance of Ethiopia (19721995): Growth Determinant and implication, Addis Ababa University. 